\title{
ESCOLA NOVA, INSTRUMENTOS TRADICIONAIS: A PRODUÇÃO DIDÁTICA DE MANOEL BERSGTRÖM LOURENÇO FILHO EM DISCUSSÃO ${ }^{1}$
}

\author{
Samira Saad Pulchério Lancillotti ${ }^{2}$
}

\begin{abstract}
RESUMO
O presente artigo tem por objetivo discutir a divergência entre a produção didática de Manoel Bersgtröm Lourenço Filho e sua reflexão sobre educação escolar, alicerçada no ideário escolanovista. Toma por objeto a Série de Leitura Graduada 'Pedrinho' e os Guias do Mestre correspondentes. A análise fundamenta-se nas teorizações marxianas sobre o trabalho e em autores que analisam a escola moderna a partir dessa categoria. Foram consultadas fontes clássicas e historiográficas vinculadas à questão em estudo. Parte-se do reconhecimento de que Comenius propôs a organização ideal para a expansão da escola moderna, quando a equiparou às manufaturas de seu tempo, o que está consubstanciado na obra Didáctica Magna, publicada em 1657. A possibilidade de universalização da escola assentou-se na sua proposição de livros didáticos, instrumentos prescritivos e homogêneos que permitiram o atendimento coletivo e simultâneo de um grande quantitativo de alunos por um único professor. Apesar de ter estabelecido críticas às práticas educativas uniformes e diretivas da escola tradicional, Lourenço Filho produziu livros didáticos marcados por essas mesmas características. É preciso ter em conta que essa parcela da produção do autor tinha em vista a educação pública, de massa, sobre uma base material que não permite conciliar expansão do ensino com sua individualização.
\end{abstract}

Palavras-chave: Manual Didático; Escola Nova; Lourenço Filho; Série de Leitura Graduada Pedrinho.

\section{PROGRESSIVE EDUCATION, TRADITIONAL TOOLS: MANOEL BERSGTRÖM LOURENÇO FILHO PRODUCTION OF DIDACTIC UNDER DICUSSION.}

\begin{abstract}
The present article has as goal to discuss the divergence between Manoel Bersgtröm Lourenço Filho production of didactic and his reflection about school education, founded on "escolanovista" ideology. It has as object "Pedrinho - A Series of Guided Reading" and its correspondent "Teacher's Guide". The analysis is based on Marxian theorization about work and on authors that analyzed the Modern School movement from this category. Classical and historical sources bounded to the issue under study were consulted. It initiates from the recognition that Comenius proposed the ideal organization in order to make expansion of the Modern School movement possible, when he equated it to the manufactures of his time, which is embodied in the work of Didáctica Magna, published in 1657. The possibility of universalization of school was settled on his proposition of didactic books, prescriptive and homogeneous instruments that allowed a collective and simultaneous support of a great quantity of students from only one teacher. Although Lourenço Filho criticized the uniform educational practices and the directives of the traditional school, he wrote didactic books marked by the same characteristics. It is necessary to take into account that this part of the author's production aimed the public and mass education, upon material basis that do not allow to conciliate teaching expansion to its individualization.
\end{abstract}

Keywords: Didactic Manual; Progressive Education; Lourenço Filho, Pedrinho - A Series of Guided Reading.

Introdução 
Uma só coisa é de extraordinária importância, pois se ela falta, pode tornar-se inútil toda a máquina, ou, se está presente, pode pô-la toda em movimento: uma provisão suficiente de livros pan-metódicos. (COMÉNIO, 1996, p. 469).

O objetivo deste artigo é promover uma discussão sobre a produção didática de Manoel Bergström Lourenço Filho (1897-1970), autor escolanovista, responsável pela disseminação de manuais didáticos ${ }^{3}$ no interior da escola pública brasileira, nas décadas de 1930 a $1970^{4}$.

Lourenço Filho destacou-se no cenário nacional e muito se tem escrito sobre sua atuação educacional no transcurso do século XX. Ressalta-se, em sua produção, a reflexão acerca das articulações entre a psicologia e a educação, aspecto bastante discutido no campo acadêmico, que reconhece seu protagonismo na consolidação da ciência psicológica no Brasil (PENNA, 1992; MONARCHA, 1997, 1999, 2001; ANTUNES, 1999, 2004; MASSIMI, 1990), entretanto, sua produção abarca diversas esferas, como atesta o perfil apresentado no Dicionário de Educadores no Brasil:

Como escritor, tratou das atividades educacionais em todos os seus níveis: desde a redação de cartilhas e livros infantis até artigos e livros sobre psicologia, estatística, educação comparada e organização e administração escolar, que obtiveram sucesso editorial e reconhecimento internacional. $\mathrm{Na}$ administração, pode-se verificar que são muitas as suas iniciativas, criando vários órgãos político-administrativos, legislando, fundando revistas e administrando coleções educacionais. Os títulos e prêmios que recebeu, o volume de sua obra, e as publicações e citações no exterior atestam seu renome internacional, além de sua decisiva influência no pensamento pedagógico e na educação brasileira. (GANDINI, R.P.C.; RISCAL, S.A., 1999, p. 371, grifo nosso).

Sua vasta obra deu lugar a inúmeras pesquisas no campo da história da educação, com temáticas e perspectivas das mais variadas. Não obstante os inúmeros estudos estabelecidos sobre a trajetória e as obras desse educador, considera-se que não foi suficientemente debatida uma contradição presente entre suas ideias e as intervenções que promoveu na base concreta das escolas brasileiras, o que se expressa em sua produção didática. Esse é o foco desta análise, que toma por objeto a Série de Leitura Graduada 'Pedrinho' e os correspondentes Guias do Mestre.

Considerado por Afrânio Peixoto, como um dos "cardeais da educação nacional"5 (MONARCHA; LOURENÇO FILHO, R., 2001, p. 15), o autor travou uma militância ferrenha pela renovação educacional, a partir dos anos de 1920. Junto aos demais reformadores, buscou infundir à educação brasileira aquele sentido, impresso pelo movimento escolanovista à educação americana e europeia ${ }^{6}$, de crítica e revisão profunda das bases, fins e meios da educação escolar, com fulcro nos avanços da biologia, psicologia e sociologia.

O esforço dos autores que se perfilaram ao movimento escolanovista afirmou-se no sentido de deslocar o mote do processo educativo do professor para o aluno, atentando para suas características individuais. Essa marca do movimento é enfatizada por Dewey, um dos principais idealizadores da Escola Nova, no seguinte trecho: 
Um objetivo educacional deve alicerçar-se nas actividades e necessidades intrínsecas (inclusive os instintos inatos e os hábitos adquiridos) do indivíduo que vai ser educado. A tendência de um objectivo como a preparação é, como já vimos, esquecer as aptidões existentes e fixar-se como fim alguma remota realização ou responsabilidade. Há em regra o pendor de terem-se em mira coisas agradáveis ao coração dos adultos e escolhe-las como fins, independentemente das aptidões dos educandos. Há também a propensão de propor objectivos tão uniformes que desprezam as aptidões especiais e exigências de um indivíduo com o esquecimento da circunstancia de que toda aprendizagem é coisa que acontece a um indivíduo em lugar e tempo determinados. (DEWEY, 1952, p. 153, grifo do autor).

Ocorre que, a despeito de assumir vigorosamente esse ideário, Lourenço Filho se destacou como autor de instrumentos didáticos diretivos, para alunos e professores, que foram disseminados no interior das escolas brasileiras desde fins da década de 1920 até $1968^{7}$. Com isso, afrontou o cerne da crítica escolanovista ao ensino tradicional considerado homogêneo, prescritivo, mecânico, antidemocrático e autoritário, por concentrar o processo educativo nas mãos do professor, norteado por instrumentos didáticos padronizados, os quais desconsideram a individualidade dos alunos.

Essa inconsistência foi insinuada por Fernando de Azevedo, em 1957, quando chamado a pronunciar-se sobre a trajetória de Lourenço Filho, nas páginas de um Livro Jubilar, organizado pela Associação Brasileira de Educação (ABE), para homenageá-lo:

A administração é a ciência do possível, e Lourenço Filho tem, como poucos, o sentido da relatividade das coisas. Não tolera a administração a rigidez e, sob o império das circunstâncias e necessidades tem, sobre pontos às vezes importantes, de inflectir a doutrina em direções diferentes, e Lourenço Filho aprendeu cedo que o ideal não se pode inserir no real sem progressivas adaptações e que é preciso afinal contar com os fatos e as situações concretas. (AZEVEDO, 1958, p. 17).

A questão foi problematizada, claramente, por Figueira, nos seguintes termos:

Apesar de o movimento da Escola Nova criticar o uso de manuais de ensino com passos metódicos e rígidos a seguir, buscando 'fornecer um repertório de informações e de referenciais críticos para o professor, orientando-lhe a leitura como prática inventiva rebelde à prescrição de modelos' (CARVALHO, 2001, p. 154), Lourenço Filho acaba por elaborar o Guia do Mestre para a Série de leitura graduada Pedrinho. O Guia e é um manual metodológico pautado e elaborado com base, segundo o autor, nos princípios escolanovistas, que oferece detalhadamente os passos que o professor deve seguir para o desenvolvimento de cada lição contida no respectivo livro do aluno. [...] Lourenço Filho adota as prescrições para a prática, embora restritas a um material específico, como um dispositivo para regular a atividade docente. As intenções renovadoras, portanto, são explicitadas num recurso bastante tradicional e largamente criticado pelo autor (FIGUEIRA, 2010, pp. 36-37).

Acerca dessa incongruência, a autora estabelece inúmeras justificativas, a partir da perspectiva da história cultural. Entre suas considerações está a de que o Guia do Mestre poderia ser considerado como um elemento de conciliação entre o novo e o velho, de modo Revista HISTEDBR On-line, Campinas, $n^{\circ}$ 71, p. 77-92, mar. 2017-ISSN: 1676-2584 
que o autor estaria apoiando em recursos tradicionais sua intenção de inovação. Pondera, também, que essa conciliação pode indicar uma interpretação particular do autor sobre o movimento e as articulações possíveis entre teoria/prática, ou que a difusão da escola nova não se deu em conformidade com a proposição de seus idealizadores.

A nosso juízo tais considerações tergiversam a questão de fundo, não avançam na compreensão das razões que impediram a generalização das práticas renovadas nas escolas, a despeito da ampla penetração desse ideário no discurso escolar ${ }^{8}$. A bem da verdade, as experiências escolanovistas exitosas ocorreram, muito pontualmente, em escolas experimentais, em condições muito diversas daquelas que marcam a educação pública em geral.

Para adentrar o debate sobre as bases da divergência entre as ideias e a obra didática do autor impõe-se, antes de tudo, uma discussão sobre a conformação da educação moderna, desde a perspectiva do trabalho, com destaque à produção do livro didático, instrumento que ocupa papel central na atividade escolar.

\section{Organização do trabalho na escola moderna}

A ampla compreensão dos percursos da escola moderna exige um mergulho no seu leito histórico. É necessário apreender a que necessidades sociais tal escola responde, como o faz e em que condições estruturais se estabelece, o que só pode ser alcançado a partir do entendimento das transformações do trabalho sob a ordem burguesa.

A escola moderna não surgiu de forma irruptiva; delineou-se, progressivamente, no bojo das transformações sociais que se estabeleceram na transição do feudalismo ao capitalismo e impuseram a disseminação de conhecimentos instrumentais para a nova ordem que emergia: leitura, escrita e cálculo.

Muitas aproximações foram feitas ${ }^{9}$ para atender à crescente demanda por educação, mas é na obra Didáctica Magna, de Jan Amós Comenius (1592-1670), publicada em 1657, que encontramos a resposta mais avançada para essa necessidade.

Naquele contexto, a expansão escolar era obstada pela desproporção quantitativa entre os que buscavam por instrução e o número de mestres aptos a assumir a tarefa de formar a juventude. Para ampliar o acesso ao conhecimento, era imperioso baratear a educação e foi justamente nesse sentido que Comenius procurou delinear uma proposta que permitisse "ensinar tudo a todos".

$\mathrm{Na}$ sua Didáctica Magna, Comenius enunciou a forma mais desenvolvida de organização escolar, adequada à universalização do ensino. Sua formulação teve por base a experiência das manufaturas de seu tempo, que revelaram as vantagens da divisão e especialização do trabalho, com o consequente desenvolvimento de novas ferramentas adequadas a tarefas parcelares. No interior da manufatura, nenhum trabalhador particular produz uma mercadoria, ela é resultante do trabalho coletivo ${ }^{10}$.

Da aplicação dessa forma de organização ao trabalho escolar resultou que parcelas do processo de trabalho do preceptor - um trabalhador com sólida formação, que tinha por base técnica o artesanato -, foram destacadas e remetidas para professores, trabalhadores especializados que passaram a responsabilizar-se por frações da formação geral da juventude.

Assim, Comenius propôs a organização das escolas em classes seriadas, conforme indica o excerto seguinte:

Agiremos à imitação do sol, se

Cada escola, ao menos cada classe, tiver um só professor. 
Para cada matéria, houver um só autor.

Para todos aqueles que estão a assistir as lições, se dispender em comum, o mesmo trabalho.

Todas as disciplinas e todas as línguas forem ensinadas com o mesmo método.

Todas as coisas forem ensinadas, a partir dos seus fundamentos, de modo breve e eficaz, de tal maneira que a inteligência se possa abrir como que com uma chave, e as coisas se lhe possam manifestar espontaneamente.

Todas as coisas que por natureza são conexas forem ensinadas em conexão umas com as outras.

E se todas as coisas se ensinarem gradualmente sem interrupções, de modo que todas as coisas aprendidas hoje sejam reforço das aprendidas ontem e uma preparação para as que se aprenderão amanhã.

Enfim, se, em tudo, se puser de parte as coisas inúteis (COMÉNIO, 1996, pp. 278-279).

Vê-se, nessa citação, o claro delineamento da escola seriada, que marca a educação moderna, na qual um único professor ensina um coletivo de alunos - a classe - , de modo simultâneo.

As classes seriam organizadas pelo critério de idade, de modo a comportar uma relativa homogeneidade no nível de desenvolvimento e compreensão dos alunos; a formação escolar se processaria gradualmente, desde a infância, passando pela puerícia e adolescência, até chegar à juventude (COMÉNIO, 1996, p. 410). Conformada nesses moldes, a educação escolar resultaria na formação do novo homem demandado pela sociedade, "[...] apto para os negócios desta vida e para a eternidade" (Ibid., p. 253).

A proposta comeniana assentou-se na proposição de um novo instrumento de trabalho, o livro didático, ou pan-metódico, tanto para os alunos como para os professores, o que fica claramente explicitado no trecho seguinte:

[...] colocar nas mãos das crianças somente os livros didácticos de que têm necessidade na sua classe, para que os outros não sejam ocasião de distracção e de confusão. [...] aos educadores da juventude, é necessário dar normas, em conformidade com as quais executem as suas obras, isto é, devem escrever-se para uso deles Livros-roteiros, que os aconselhem quanto ao que hão de fazer, em que lugar e de que modo, para que se não caia em erro. Os livros didácticos serão, portanto, de dois géneros: verdadeiros livros de texto para os alunos, e livros-roteiros (informatorii) para os professores, para que aprendam a servir-se bem daqueles. (COMÉNIO, 1996, p. 460, grifos nossos).

Como se vê, a cada classe seria destinado um livro específico para os alunos, acompanhado de um livro roteiro para o professor. A simplificação e objetivação do trabalho aludidas nesse trecho sinalizam por quais caminhos Comenius logrou oferecer novos quadros ao magistério. Por meio do livro didático, foi possível substituir o trabalho complexo, realizado por mestres sábios, que tinham pleno domínio do conhecimento e eram capazes de conduzir integralmente a educação de seus discípulos, por trabalho simples, dos professores, trabalhadores especializados que, guiados por um instrumento didático prescritivo, passaram a incumbir-se de parcelas da formação geral dos educandos, atendidos coletiva e simultaneamente, na escola seriada.

Ao enfatizar as vantagens de seu método de instrução, que considera perfeito e universal, Comenius argumenta: 
[...] louvamos o método universal [...] de tal maneira que: 1 . com um menor número de professores, se possa ensinar um número muito maior de alunos, que com o método até aqui usado; 2. e os alunos se tornem verdadeiramente instruídos; 3 . e recebam uma instrução polida e cheia de gravidade; 4. e se admitam a essa cultura mesmo aqueles que não são dotados de grandes inteligências e até os de inteligência lenta; 5. finalmente, serão hábeis para ensinar, mesmo aqueles a quem a natureza não dotou de muita habilidade para ensinar, pois a missão de cada um não é tanto tirar da própria mente o que deve ensinar, como sobretudo comunicar e infundir na juventude uma erudição já preparada e com instrumentos também já preparados, colocados nas suas mãos. [...] porque não há-de o professor ensinar na escola todas as coisas, se tudo aquilo que deverá ensinar e, bem assim, os modos como o há-de ensinar, o tem escrito como que em partituras? (COMÉNIO, 1996, p. 457, grifos nossos).

Com essa formulação se evidencia que, mesmo sendo capaz de ensinar mais do que sabe, o professor não tem controle sobre o processo de trabalho, é um executor de ações que foram planejadas e propostas por outrem. A desqualificação do trabalho docente permitiu não apenas ampliar o número de educadores, como também remunerá-los em um patamar muito inferior àquele dos preceptores. Ao tornar-se o "professor do professor" (ALVES, 2015, p. 33), o livro didático passou a se constituir como elemento central no processo educativo.

Assim, nos moldes descritos, o trabalho docente assumiu a conformação de trabalho social, compatibilizando-se com as transformações do trabalho sob o capitalismo.

A proposta comeniana está na base da educação escolar moderna, que só veio a conformar-se mais claramente a partir da segunda metade do século XIX, quando a escolarização da juventude se impôs como uma necessidade social mais abrangente e foram progressivamente instituídos os Sistemas Nacionais de Ensino.

Com os sistemas de ensino, a educação escolar assumiu uma organização progressivamente complexificada, sujeita à normatização jurídica particular, passando a ser regulada por programas específicos, a depender do nível de ensino; marcada pelo uso de técnicas e recursos próprios; ordenada por calendário determinado; e, além disso, confiada a profissionais especializados, os professores. É por meio do sistema de ensino que a sociedade regulamenta quem pode exercer o trabalho docente, quais níveis de ensino deve propor e as condições de formação adequada para o desempenho do trabalho nos distintos níveis, ou para ministrar cada disciplina que os compõem, na medida em que essas vão sendo definidas (LANCILLOTTI, 2008, p. 223).

No interior dos Sistemas Nacionais de Ensino, prevaleceu o modo coletivo/simultâneo de ensinar, naqueles mesmos moldes propostos por Comenius no século XVII, que correspondem à organização manufatureira do trabalho. Foi dessa forma que a escola moderna veio a se consolidar no século XX, nos países de economia mais desenvolvida.

\section{Permanências na "renovação escolar"}


A organização da escola moderna vem sendo colocada em questão desde a transição do século XIX para o XX, tendo sido reputada, pelos autores escolanovistas como tradicional, antidemocrática e inadequada às necessidades da sociedade capitalista industrial, que já se encontrava em franca e acelerada transformação.

Como alternativa, propôs-se uma revisão profunda dos meios e fins da escola, de modo a contemplar o desenvolvimento das aptidões e capacidades individuais - esse o mote da escola nova, como já salientado - e vários ensaios foram feitos no sentido de superar tal forma de organização do trabalho, podendo ser referidas as propostas de Kilpatrick, com o seu "sistema de projetos"; os "centros de interesse", de Ovídio Decroly; o "Método Montessoriano", de Maria Montessori; o "Plano Dalton", de Helena Parkust, dentre outras (LOURENÇO FILHO, 1961).

Ao salientar os aspectos típicos da educação tradicional, com assumido exagero, e sinalizar os rumos da educação nova, Dewey pronunciou-se nos termos seguintes:

\begin{abstract}
Aquilo que a caracteriza pode ser resumido se dissermos que o seu centro de gravidade é exterior à criança. Situa-se no professor, no manual, em qualquer parte e em toda a parte excepto nos instintos e nas atividades imediatas da própria criança. [...] a mudança que tem vindo a ser introduzida na educação é uma transferência do centro de gravidade. [...] no caso em análise a criança converte-se no Sol em volta do qual gravitam os instrumentos da educação; ela é o centro em torno do qual estes se organizam (DEWEY, 2002, p. 40, grifos nossos).
\end{abstract}

Ainda segundo o autor, a personalidade e o caráter do aluno ganham prevalência sobre o programa escolar de modo que a criança passa a constituir o ponto de partida, meio e fim da educação, "O objectivo não é o conhecimento ou a informação, mas a realização pessoal." (DEWEY, 2002, p. 161).

Alinhado a esse ideário, Lourenço Filho publicou, em 1930, a obra "Introdução ao Estudo da Escola Nova", pela editora Companhia Melhoramentos de São Paulo, inserida na Coleção Bibliotheca de Educação, organizada e dirigida por ele. Nesse livro, sistematizou informações sobre as bases históricas e técnicas (biológicas, psicológicas e sociológicas) do movimento da Escola Nova; ofereceu descrição e análise comparativa dos "sistemas didáticos" modernos ${ }^{11}$, além de delinear e debater a problemática da ação intencional de educar, de seus fins e meios, desde uma perspectiva filosófica e política.

A obra, que foi apontada por Alceu de Amoroso Lima como "[...] um livro chave da nossa cultura contemporânea", teve treze edições publicadas, sendo a última de 1979 (MONARCHA; LOURENÇO FILHO, R., 2001, p. 61). O texto foi ampliado e sofreu revisões no decurso desse tempo, com vistas à atualização de seu conteúdo. Foi publicado em espanhol, tendo sido adotado como referência para a formação de quadros para o magistério em institutos nacionais e universidades latino-americanas.

Numa explanação sobre os princípios gerais da Escola Nova, Lourenço Filho afirmou o respeito à "personalidade do educando" e o reconhecimento de sua liberdade:

Cada educando há de desenvolver-se segundo suas próprias capacidades e recursos, por ação e esforço individual. O impulso vital exprime uma exigência de criação, que deverá resultar numa síntese de ordem dinâmica ou funcional, só possível de realizar-se pelo indivíduo no indivíduo, como ser unitário que harmonize tendências e conflitos. Ora, isso leva a combater o aspecto impositivo da educação tradicional, caracterizado pelo apêlo ao 
automatismo, com eliminação do valor dos impulsos naturais, desejos e propósitos, fontes do sistema vital que é a personalidade (LOURENÇO FILHO, 1961, pp. 244-245).

O autor complementou a ideia, afirmando que não se tratava, entretanto, de abandonar o educando, o que implicaria a negação da tarefa educativa, mas sim de conduzir a educação para uma "liberação progressiva".

Lourenço Filho fez a defesa de uma compreensão funcional do processo educativo, tanto de um ponto de vista social como individual, de modo que caberia à escola assegurar os meios para o desenvolvimento pleno do educando, a partir de sua própria atividade, visando a finalidades por ele definidas. Afirmadas tais condições "[...] a vida e o mundo poderão unir os indivíduos e os povos, em ideais sempre mais elevados de trabalho produtivo e concórdia universal." (LOURENÇO FILHO, 1961, p. 246).

Com base em conhecimentos advindos da psicologia, biologia e sociologia, o autor problematizou e analisou questões concernentes a diversos fatores como: maturação, hereditariedade, adaptação, aprendizagem, interesse, motivação, atividade, interações entre os homens e desses com o meio. As formulações teóricas sobre as fases de desenvolvimento foram reconhecidas por Lourenço Filho como instrumentais para a planificação e graduação do desenvolvimento de habilidades, das mais básicas, como a fala, às mais complexas, como o domínio de leitura/escrita.

Sua preocupação com a problemática da alfabetização levou-o a publicar a obra: TESTES ABC: Para a verificação da maturidade necessária à aprendizagem da leitura e da escrita, em 1933, com finalidades diagnósticas e prognósticas, tendo em vista a formação de classes homogêneas que facilitassem o processo de alfabetização dos escolares. Considerou o autor que:

\begin{abstract}
Na escola popular, a leitura e a escrita representam o problema crucial, que nenhum argumento logra iludir. A cultura não é apenas a Escola de primeiras letras extensa, mas, onde quer que uma escola popular esteja aberta, tradicional ou renovada, o problema da leitura e da escrita é daqueles que, ao mestre, se apresenta como fundamental, tanto pelas exigências da organização do ensino graduado, quanto pelos reclamos sociais (LOURENÇO FILHO, 2008, p. 20).
\end{abstract}

Ainda na intenção de ampliar o alcance da escola pública e o acesso à leitura e escrita, o autor produziu cartilhas e manuais didáticos que tiveram grande penetração na educação brasileira. Entre essa parcela da produção do autor encontra-se a Série de Leitura Graduada 'Pedrinho', e seus respectivos Guias. A Série Pedrinho é composta pelos seguintes títulos: Pedrinho/1953; Pedrinho e seus amigos/1954; Aventuras de Pedrinho/1955; Leituras de Pedrinho e Maria Clara/1956. Em 1957, Lourenço Filho publicou a cartilha Upa, Cavalinho!, livro inicial da Série. Há, ainda, referência, na obra de Lourenço Filho, a um último livro, Pedrinho e o Mundo, que parece não ter sido publicado (MONARCHA, C.; LOURENÇO FILHO, R., 2001, p.132; FIGUEIRA, 2010, p. 9).

Quanto aos Guias, foram lançados, inicialmente, de modo independente, sendo editados concomitantemente aos três primeiros livros da série, (1953, 1954 e 1955). Em 1956, o autor fez publicar o Guia do mestre para a cartilha Upa, Cavalinho! e, em 1968, publicou o Guia do mestre para o ensino da leitura, em dois volumes. O primeiro volume com aplicação prática à cartilha Upa, Cavalinho! e ao primeiro livro, Pedrinho. O segundo volume correspondia aos demais livros da série, Pedrinho e seus amigos; Aventuras de Pedrinho e Leituras de Pedrinho e Maria Clara. Tal produção tinha o sinete do movimento 
escolanovista, que se insurgiu contra o trabalho escolar vigente no período e propôs alçar a escola aos desafios do novo tempo.

Nos quatro livros da Série Pedrinho o autor acrescenta, ao final, uma mensagem "Aos Srs. Professôres". No primeiro livro, ao abordar a estrutura da Série como um todo, sinaliza:

Sua organização obedece a dois princípios capitais: rigorosa graduação do material que oferece, e compreensão de que o ensino da leitura exige estreita cooperação, não só entre o professor e o aluno, como também entre os objetivos que os livros tenham em vista e as situações que a escola deva proporcionar, a fim de que os seus efeitos educativos venham a ser plenamente alcançados (LOURENÇO FILHO, 1961, p. 125).

Fica evidente nesse excerto o papel relevante que o livro didático assume, de norteador do processo educativo ao qual a escola deve submeter-se, com vistas ao alcance dos objetivos delineados. Avançando na abordagem sobre a necessária cooperação entre o livro e a escola, o autor destacou que a série vem acompanhada de um Guia do Mestre para cada volume nos quais são estabelecidos, além dos objetivos das lições propostas:

[...] as formas de preparação do trabalho e verificação de seu rendimento, a indicação de exercícios e jogos, bem como sugestões muito variadas para que a aprendizagem da leitura se integre nas demais formas da linguagem, e ainda na das demais disciplinas do programa. (LOURENÇO FILHO, 1961, p. 125).

Claro está que os objetivos estão pré-definidos e graduados, bem como os demais passos do trabalho docente e, evidentemente, esses procedimentos não condizem com a proposta de uma educação "centrada no aluno", fundada em suas necessidades, interesses, aptidões e personalidade.

O reconhecimento, por parte de Lourenço Filho, da conveniência de manuais prescritivos, aparece cristalino no cotejamento do livro do aluno com o Guia do Mestre, como se depreende da apresentação ao primeiro volume, na qual o autor destaca:

Ninguém desconhece que, em nosso país como em outro qualquer, a formação recebida nas escolas normais não pode ser completa. Terá de prosseguir através da experiência de vida dos mestres, quando satisfatória orientação lhes seja proporcionada, por vários modos, inclusive por manuais dêste tipo. Tal é a razão por que, em países mesmo de mais adiantada organização escolar, os Estados Unidos, por exemplo, as séries de leitura escolar são acompanhadas de 'livros do mestre', ou guias, como êste (LOURENÇO FILHO, 1967, p. 6, grifos nossos).

O autor alude à formação dos professores que, mesmo em países com sistemas de ensino avançados, seria insuficiente para responder aos auspícios de uma educação renovada, calcada na individualidade do aluno. A observação implica o reconhecimento de que os manuais didáticos se revelam ferramenta indispensável à expansão escolar, ainda que a formação de professores normalistas já tenha se instalado. Se isso é verdadeiro nos países mais avançados, sobreleva-se no Brasil, país de dimensões continentais, em que a proposição de um sistema escolar mal ensaiava os primeiros passos. É o que se evidencia no seguinte excerto: 
Essa situação é ainda mais premente no caso dos docentes que não hajam recebido formação em escolas normais. Não se deverá esquecer que, em nosso país, êsses mestres representam percentagem muito elevada, nada menos que $48 \%$ ou quase metade do total do magistério primário. De regra, êsses professôres são pessoas interessadas pelo ensino, desejosas de bem realizar o seu trabalho, mas carentes de maior orientação, a qual não chega a ser completada, também, nos chamados cursos de 'capacitação'. Não será exagêro afirmar, portanto, que este 'Guia', em qualquer dos casos, vem ao encontro de reais necessidades do ensino, tais como as sentem milhares de mestres, desejosos de melhorar seu trabalho, ainda quando diplomados, ou mesmo quando já possuam maior tirocínio, não realizado, porém, sob direção mais constante. (LOURENÇO FILHO, 1967, p. 6, grifos nossos).

Lourenço Filho reconhece que a expansão da educação só pode lastrear-se na divisão, simplificação e objetivação do trabalho, contribuindo para a consolidação da escola manufatureira, tal como formulada por Comenius, no século XVII.

Sua descrição dos aspectos inovadores da Série reforça, contraditoriamente, o seu caráter de manutenção, como expressa o trecho que segue:

Note-se que esta publicação não se apresenta como simples receituário que pretenda substituir uma rotina por outra. [...] Expondo e comentando as situações da aprendizagem, livro a livro e lição a lição, como se apresentam elas na 'Série Pedrinho', estas páginas as relacionam com os princípios que os mestres deverão ter em mente, não só na fase inicial da aprendizagem da leitura, mas em tôdas elas; explica como se deverá observar e analisar cada situação de aprendizagem; orienta os que ensinam a melhor compreender as diferenças individuais dos alunos e a aplicar os recursos de motivação; indica os modos mais simples e atraentes de associar a leitura aos exercícios das demais disciplinas, demonstra como os diferentes passos da aprendizagem devem ser relacionados quanto aos objetivos de mais largo alcance educativo; instrui, enfim, sobre os recursos a empregar na avaliação do trabalho dos alunos e na avaliação do trabalho dos próprios professôres. (LOURENÇO FILHO, 1967, pp. 6-7, grifos nossos).

Pode-se sempre argumentar que o conteúdo desses manuais e guias é muito distinto daquele proposto por seus precedentes, e não poderia ser diferente, já que as condições concretas e as demandas sociais são de outra ordem. Aqui avultam os avanços das ciências que servem de fundamento à pedagogia e lhe conferem um caráter mais técnico; contudo, é imperioso destacar que, a despeito de todo o discurso em contrário, a proposta de Lourenço Filho não toca a organização manufatureira do trabalho e não vai além de "substituir uma rotina por outra".

Sobre esse ponto, é importante indicar que autores escolanovistas fizeram críticas incisivas aos manuais didáticos. Nesse sentido, é muito reveladora a reflexão estabelecida por Fernando de Azevedo em discurso pronunciado no encerramento da Semana do Livro, realizada na Universidade de São Paulo, em outubro de 1933, no qual aborda "A renovação educacional e o livro". Pondera o autor:

O livro de texto, na escola tradicional, e o livro escolar, na educação nova, distinguem-se apenas por uma diferença fundamental de função. 
Ele não desaparece da escola nova, mas assume uma 'nova função', tão importante, tão larga e tão profunda, que já não bastaria, para cada matéria, o único livro: o livro de leitura, o livro de texto. Já será preciso que se multipliquem os livros sobre cada matéria, para que o escolar possa manuseá-los quando necessitar, utilizando-os como 'instrumentos de trabalho' e auxiliares, aos quais tem de recorrer para obter dados e informações, esclarecer dúvidas, recolher material de estudos e de reflexão, e 'por simples prazer', que assim o fará a criança por própria iniciativa, quando o livro assumir, para ela o valor de mais um 'elemento de cultura', e ela possa ler, na biblioteca escolar, não o livro que se lhe impõe, mas de todos ao seu alcance aqueles que lhe agrada ler, que a interessaram, por atenderem melhor aos seus gostos, às suas tendências e às suas necessidades (AZEVEDO, 1958, p. 198, grifos nossos).

Evidencia-se com clareza na exposição do autor que, diferentemente do "livro de texto", o "livro escolar" ocuparia papel relevante no interior das práticas educativas norteadas pelos princípios da Escola Nova, pois seria utilizado livremente pelos escolares, de acordo com seus próprios interesses e necessidades. Azevedo ainda destacou e criticou o caráter central e excludente do "livro de texto", na escola tradicional:

No ponto de vista da escola tradicional, em que a direção do trabalho se atribui sempre à iniciativa do professor, o 'livro de texto' assume a função absorvente, quase despótica, de regulador de atividades, como imposição ao natural desenvolvimento do espírito infantil e absoluta indiferença ante as suas necessidades e interesses (AZEVEDO, 1958, p. 197).

Com essas considerações, o autor conclui que, se na escola tradicional o "livro de texto" é instrumento de trabalho do professor, na perspectiva da escola nova, o "livro escolar" passa a ser instrumento de trabalho dos educandos.

Apesar de toda a argumentação e teorização dos autores escolanovistas, o que prevalece nas escolas contemporâneas é o "livro de texto", usando aqui a expressão formulada por Comenius que é privilegiada por Azevedo. Esse material prescritivo está presente, inclusive, no próprio campo da Escola Nova, como traduz a produção de didática de Lourenço Filho.

Não obstante todo o esforço dos reformadores, o centro do processo educativo não se ateve ao professor ou ao aluno, mas sim, aos instrumentos didáticos, que mantêm a centralidade do processo educativo no interior da escola moderna. A este respeito registra Alves:

A relação educativa não esteve centrada no professor, dentro da escola
tradicional, nem se deslocou para o aluno na escola nova. Em ambos os
casos, a relação educativa sempre esteve centrada no instrumento de
trabalho. Como o manual didático, desde sua emergência na escola
moderna, colocou-se na condição de instrumento por excelência do
trabalho didático, a sua funça e o seu conteúdo é que devem ser
desentranhados pela pesquisa para que ganhem significado histórico e
inteligibilidade (ALVES, 2011, p. 280).

A despeito da ampla propagação do ideário renovador e das inúmeras propostas delineadas a partir daqueles princípios, a escola se manteve aferrada à organização tradicional. 
Quando se defrontou com a tarefa de levar a proposta renovadora para o interior das escolas, Lourenço Filho não logrou suprimir esse instrumento de trabalho. A rigor, sua "Série de Leitura Graduada Pedrinho", acompanhada do "Guia do Mestre", não difere, a menos em conteúdo, dos manuais propostos por Comenius, no Século XVII, que propôs dois tipos de livros didáticos, os livros de texto, para os alunos e os livros-roteiros para os professores. A problemática ganha relevo exatamente por se tratar de um crítico do ensino homogêneo e prescritivo, um proeminente intelectual do movimento escolanovista, reconhecido internacionalmente.

Para compreender a divergência entre as ideias e a produção do autor é preciso ter em conta que a atuação de Lourenço Filho se estabeleceu em ampla escala, visando à organização da educação pública, de massa, sobre uma base material dada, condição que tem fugido ao escopo das análises já estabelecidas.

Os reformadores defrontaram-se com a tarefa de conciliar a expansão escolar com a individualização do ensino e muitos se empenharam na busca por novas respostas, entretanto as diversas propostas não tiveram força para se generalizar, "[...] mantiveram-se adstritas a escolas de aplicação, ou tiveram elementos parciais sendo incorporados pelas escolas convencionais, em arranjos ecléticos, nos quais se observa o predomínio do modo simultâneo de ensinar." (LANCILLOTTI, 2008, p. 312).

Apesar de toda a crítica de que foi alvo, o ensino simultâneo, homogêneo ainda prevalece na escola contemporânea Os manuais didáticos, tão criticados, continuam sendo utilizados massivamente na educação, em todos os níveis de ensino. São fontes privilegiadas, senão exclusivas, da educação escolar (ALVES, 2001, 2005, 2006; LANCILLOTTI, 2008).

Mas, o que confere permanência à organização manufatureira do trabalho didático ${ }^{12}$, calcada no uso do manual didático comeniano?

Considera-se que tal condição decorre, fundamentalmente, da natureza imaterial ${ }^{13}$ do trabalho docente, que obsta sua plena objetivação e, por conseguinte, o avanço naquela forma mais desenvolvida de produção que se consubstancia na indústria moderna.

Sobre a base técnica manufatureira, ainda que se estabeleça a divisão, simplificação e objetivação do processo de trabalho, o trabalhador mantém algum controle sobre parcelas da atividade produtiva. A indústria moderna, por seu lado, implica um grau de desqualificação do trabalho muito mais amplo, na medida em que o processo de produção é grandemente automatizado e converte o operário em mero apêndice da máquina.

Se esse grau de objetivação foi alcançado nos ramos da indústria eletromecânica, ainda no século XIX ${ }^{14}$, o mesmo não ocorreu naquelas esferas de produção que não puderam se independentizar da barreira orgânica do trabalho (LANCILLOTTI, 2008). É este o caso do trabalho docente que, apesar de todos os avanços tecnológicos feitos até o presente, não permite automação, particularmente quando se trata daqueles níveis de ensino que constituem a educação básica, nos quais as relações dos alunos com o professor são marcadamente heterônomas.

Isso contraria fortemente o apelo à autonomia do estudante para "construir seu conhecimento", tal perspectiva é insuficiente para dar acesso ao conhecimento socialmente acumulado que é a função precípua da escola e impõe a ação docente. Esse discurso encontra lastro exatamente naquelas formulações dos escolanovistas que emergiram há pouco mais de um século e ganharam força no transcurso do século XX, o que inclui a contribuição de Lourenço Filho.

\section{Considerações finais}


Tendo em vista a discussão estabelecida, não é de surpreender a contradição presente entre as ideias do autor e sua intervenção nas práticas concretas da escola de seu tempo. Todas as reformas e modificações instauradas na educação escolar de massa, nesse entretempo, não entraram em contradição com a organização manufatureira do trabalho didático, condicionada pelo grau de desenvolvimento material alcançado na sociedade presente.

Ainda que as teorias educacionais e os conteúdos escolares tenham se modificado ao longo do tempo, não se observa qualquer transformação mais expressiva na organização do trabalho e no ferramental colocado a serviço da tarefa educativa, ressalvando algumas experiências pontuais desenvolvidas em escala muito reduzida. $\mathrm{O}$ que se constata na escola contemporânea é a permanência da organização manufatureira marcada por progressiva constrição e controle do trabalho didático.

Não havendo forma possível de incorporar o trabalho docente em um maquinismo autônomo, define-se, de antemão e de modo rigoroso, como o processo de trabalho deverá ser conduzido com vistas a finalidades determinadas. O trabalho vivo persiste como base da "fábrica de ensinar", mas, ao trabalhador, quase não resta autonomia, pois essa se encontra cerceada, por um lado, pelos parâmetros e diretrizes curriculares e, por outro, pelas inúmeras avaliações em larga escala que fazem a conferência do produto resultante da atividade escolar. E é o manual didático que conduz e norteia a prática diuturna das salas de aula, que define os objetivos, conteúdos, recursos, procedimentos e avaliações a serem executados em um dado tempo/espaço, com vistas à formação das novas gerações nos moldes planejados.

Apesar de séculos transcorridos desde a proposta comeniana de "ensinar tudo a todos", a sociedade não encontrou novas formas de responder a tal desafio, e a escola moderna ainda está muito distante de atender a essa demanda em um patamar de quantidade/qualidade que supere a educação instrumental oferecida sobre a base manufatureira.

\section{Referências}

ALVES, G. L. A Produção da Escola Pública Contemporânea. Campinas,SP: Autores Associados, Campo Grande: UFMS, 2001.

ALVES, G. L. O Trabalho Didático na Escola Moderna: formas históricas. Campinas,SP: Autores Associados, 2005.

ALVES, G. L. A Produção da Escola Pública Contemporânea. 4. ed. Campinas, SP: Autores Associados, 2006.

ALVES, G. L. A centralidade do instrumento de trabalho na relação educativa: a escola moderna brasileira nos séculos XIX e XX. In: GONÇALVES NETO, W. et al. (Orgs.) Práticas escolares e processos educativos: currículo, disciplinas e instituições escolares [séculos XIX e XX]. Vitória, ES: EDUFES, 2011.

ALVES, G. L. (Org.) Textos escolares no Brasil: clássico, compêndios e manuais didáticos. Campinas,SP: Autores Associados, 2015.

ANTUNES, M. A. M. A Psicologia no Brasil: leitura histórica sobre sua constituição. São Paulo: EDUC; Unimarco, 1999. 
ANTUNES, M. A. M. (Org.) A Psicologia no Brasil - Primeiros ensaios. Rio de Janeiro: EDUERJ, 2004.

AZEVEDO, F. A educação e seus problemas. 4. ed. São Paulo: Edições Melhoramentos. 1958, t.1, v.8.

AZEVEDO, F. Diálogo de uma vida com a educação. In: Um educador brasileiro: Lourenço Filho; livro jubilar organizado pela Associação Brasileira de Educação. São Paulo: Melhoramentos, 1959.

BERTOLETTI, E.N.M. Lourenço Filho e a alfabetização: um estudo de Cartilha do Povo e da cartilha, Upa, Cavalinho! São Paulo: UNESP, 2006.

COMÉNIO, J. A. Didáctica Magna: tratado da arte universal de ensinar tudo a todos. 4.ed. Lisboa, PT: Calouste Gulbekian, 1996.

DEWEY, J. Democracia e Educação: breve tratado de fillosofia da educação. 2. ed. São Paulo: Companhia Editora Nacional, 1952-

DEWEY, J. A escola e a sociedade e a criança e o currículo. Lisboa, PT: Relógio D’água, 2002.

FIGUEIRA, P.F.F. Lourenço Filho e a Escola Nova no Brasil: estudo sobre os Guias do Mestre da série graduada de leitura Pedrinho. Araraquara: 2010. Dissertação (Mestrado em Educação) - Unesp/Araraquara.

GANDINI, R.P.C.; RISCAL, S.A. Manoel Bergtröm Lourenço Filho. In: FÁVERO, M.L.A; BRITTO, J.M., (orgs.), Dicionário de Educadores no Brasil. Rio de Janeiro: UFRJ, MEC-INEP, 1999, p. 365-373.

LANCILLOTTI, S. P. A constituição histórica do processo de trabalho docente.

Campinas: 2008. Tese (Doutorado em Filosofia e História da Educação) - Unicamp

MASSIMI, M. História da psicologia brasileira: da época colonial até 1934. São Paulo: EPU, 1990.

LOURENÇO FILHO, M.B. Pedrinho. 11. Ed. São Paulo: Melhoramentos, 1961.

LOURENÇO FILHO, M.B. Guia do Mestre para o ensino da leitura. São Paulo: Melhoramentos, 1967 v.1.

LOURENÇO FILHO, M.B. Introdução ao Estudo da Escola Nova. 7. Ed. São Paulo: Melhoramentos, 1961. v.2.

LOURENÇO FILHO, M.B. Testes $A B C$ : para verificação da maturidade necessária à aprendizagem da leitura e escrita. 13a. ed. Brasília: Instituto Nacional de estudos e pesquisas Educacionais Anísio Teixeira, 2008. 
MARX. K. O Capital - O processo de produção do capital. Livro 1, v. I. 9. ed. São Paulo: DIFEL, 1984.

MARX. K. Teorias da Mais-valia. v. I. São Paulo: Difel, 1980.

MONARCHA, C. (org.). Lourenço Filho: outros aspectos, mesma obra. Mercado de Letras, Campinas, 1997.

MONARCHA, C. Lourenço Filho e a organização da psicologia aplicada à educação. Brasília: INEP, 2001.

MONARCHA, C.; LOURENÇO FILHO, R. (orgs.) Por Lourenço Filho: uma biobibliografia. Brasília: INEP/MEC, 2001.

MONARCHA, C. A Escola Normal da Praça: o lado noturno das luzes. Campinas,SP: Unicamp, 1999.

PENNA, A. G. História da psicologia no Rio de Janeiro. Rio de Janeiro: Imago, 1992.

Notas

1 Este artigo é parte de Pesquisa interinstitucional, intitulada: "A Organização do Trabalho Didático na Perspectiva de Educadores da Escola Nova (1930-1970)", que conta com apoio financeiro do CNPq.

${ }^{2}$ Dr $^{\mathrm{a}}$ em História e Filosofia da Educação. Professora da Universidade Estadual de Mato Grosso do Sul/UEMS. (samira.1@uol.com.br - Universidade Estadual de Mato Grosso do Sul - UEMS)

${ }^{3}$ Neste estudo são utilizados os termos manual didático e livro didático como sinônimos.

${ }^{4}$ Mortatti indica que "[...] já educador renomado e autor de vários livros e artigos sobre e psicologia, Lourenço Filho produz outras cartilhas de alfabetização [antecedidas pela Cartilha do povo: para ensinar a ler rapidamente, publicada em 1928], livros de leitura, 'guias do mestre', 'livro do aluno', livros de literatura infantil e organiza série de exercícios de aritmética, além de continuar orientando, revisando e atualizando livros didáticos e de literatura infantil." (In: MONARCHA, C.; LOURENÇO FILHO, R, 2001, p. 127).

${ }^{5}$ Junto a Fernando de Azevedo e Anísio Teixeira.

${ }^{6}$ Sob influência de John Dewey, nos Estados Unidos; Edouard Claparède, na Suíça e Maria Montessori, na Itália, dentre outros.

${ }^{7}$ Em janeiro de 1984, foi publicada a última edição da Cartilha do Povo (1928), com uma tiragem de 5.000 exemplares (MONARCHA, C.; LOURENÇO FILHO, R. 2001, p. 306).

${ }^{8}$ Bertoletti destaca que o movimento escolanovista se sustentou, no Brasil, por aproximadamente sete décadas e que as ideias e obras de seus autores continuam inquietando os estudiosos da educação (BERTOLETTI, 2006, pp. 98-99).

${ }^{9}$ Dentre os antecessores da proposta comeniana podem ser referidas as contribuições dos Irmãos da Vida Comum, da Companhia de Jesus, de John Sturm e Wolfgang Ratke (LANCILLOTTI, 2008).

${ }^{10}$ A esse respeito Marx observa: "O mecanismo específico do período manufatureiro é o trabalhador coletivo, constituído de muitos trabalhadores parciais. As diferentes operações executadas sucessivamente pelo produtor de uma mercadoria e que se entrelaçam no conjunto de seu processo de trabalho, apresentam-lhe exigências diversas. [...] Depois de separar, tornar independentes, isolar essas diversas operações, são os trabalhadores separados, classificados e grupados segundo suas qualidades dominantes." (1984, p. 400). 
${ }^{11}$ Abarcando desde a formulação de Wolfgand Ratke (1571-1655) e João Amos Comenius (1591-1670), no século XVII, passando por J. H. Pestalozzi (1746-1827); J. J. Rousseau (1712-1778) e J. F. Herbart (17761841) no século XVIII, chegando às proposições dos autores mais destacados do movimento escolanovista, o que inclui o Método Montessoriano; o Sistema Decroly, com foco em centros de interesse e o Método de Projetos de W. H. Kilpatrick.

${ }^{12}$ Segundo Alves (2005), a organização do trabalho didático implica: uma relação educativa entre uma "forma história de educador" e uma "forma histórica de educando", mediada por recursos didáticos (conteúdos, tecnologias educacionais e procedimentos técnico-pedagógicos) em um espaço físico determinado. (p. 1011). Vale ressaltar que com o aprofundamento da divisão do trabalho na escola moderna, foram dissociadas as esferas de planejamento e execução do trabalho didático, dando lugar a inúmeras funções especializadas. Ainda, conforme Alves: "[...] o trabalho didático fez germinar diversas modalidades de trabalhadores especializados dentro da escola moderna. Entre outros, tiveram origem o administrador de unidades escolares e os seus subordinados, responsáveis pelas tarefas de administração de pessoal, de controle de vida escolar, de controle financeiro, de controle de material, de manutenção e de limpeza desses estabelecimentos." (In: GONÇALVES NETO et. al., 2011, pp. 283-284). Compreende-se que o trabalho docente é parte constitutiva do trabalho didático, cingindo-se à execução da tarefa educativa no âmbito da aula.

${ }^{13}$ Marx incluiu o trabalho dos professores entre as formas de produção imaterial uma vez que: "A produção é inseparável do ato de produzir, como sucede com todos os artistas executantes, oradores, atores, professores, médicos, padres etc. Também aí, o modo de produção capitalista só se verifica em extensão reduzida e, em virtude da natureza dessa atividade, só pode estender-se a algumas esferas. Nos estabelecimentos de ensino, por exemplo, os professores, para o empresário do estabelecimento, podem ser meros assalariados; há um grande número de tais fábricas de ensino na Inglaterra" (MARX, 1980: pp.403404, grifos nossos).

${ }^{14}$ Nos ramos Industriais: têxtil, químico e siderúrgico.

Recebido: Abril/2017.

Aprovado: Junho/2017. 